\title{
Report on the 7th International Congress of IMACSSS and the 4th World Scientific Congress of Sports and Martial Arts
}

\author{
John A. JOHNSON* \\ Department of Taekwondo, College of Physical Education, Keimyung University (Republic of Korea)
}

Recepción: 02/10/2018; Aceptación: 17/12/2018; Publicación: 20/12/2018.

\begin{abstract}
This report outlines the $7^{\text {th }}$ International Congress of the International Martial Arts and Combat Sports Scientific Society (IMACSSS) and the $4^{\text {th }}$ World Scientific Congress of Sports and Martial Arts (Rzeszow, Poland, October 17-19, 2018) to provide constructive criticism for future conferences. The conference drew numerous scholars from four continents and showcased research on both well-known martial arts and combat sports (e.g., Judo and Taekwondo), while providing a spotlight for less-researched arts (e.g., Malaysia's Silat and various Polish art forms) as well. Presentations were on qualitative and quantitative research and spanned several academic disciplines. While the three-day conference was organized well and expertly run, slight changes to the schedule could maximize participants' overall experience at future IMACSSS events.
\end{abstract}

Keywords: Martial arts; combat sports; scientific research; scientific meetings; congresses; IMACSSS.

\section{Informe sobre el 7th International Congress of IMACSSS and the 4th World Scientific Congress of Sports and Martial Arts}

\section{Resumen}

Este informe describe el 7 th International Congress of the International Martial Arts and Combat Sports Scientific Society (IMACSSS) y $4^{\text {th }}$ World Scientific Congress of Sports and Martial Arts (Rzeszow, Polonia, 17-19 de octubre, 2018), y aporta una crítica constructiva para futuras conferencias. La conferencia reunió numerosos académicos de cuatro continentes y mostró investigaciones sobre las artes marciales y deportes de combate más conocidas (e.g., judo y taekwondo), así como sobre otras menos investigadas (e.g., el silat de Malasia o diversas artes marciales polacas). Las presentaciones mostraron estudios de tipo cualitativo y cuantitativo, y abarcaron diversas disciplinas académicas. Si bien la conferencia, de tres días de duración, estuvo bien organizada y dirigida, algunos pequeños cambios en la programación podrían maximizar la experiencia general de los participantes en los futuros eventos de la IMACSSS.

Palabras clave: Artes marciales; deportes de combate; investigación científica; reuniones científicas; congresos; IMACSSS.

\section{Relatório sobre o 7th International Congress of IMACSSS e 4th World Scientific Congress of Sports and Martial Arts}

\section{Resumo}

Este resumo descreve o $7^{\text {th }}$ International Congress of the International Martial Arts and Combat Sports Scientific Society (IMACSSS) e $4^{\text {th }}$ World Scientific Congress of Sports and Martial Arts (Rzeszow, Polônia, 17-19 outubro, 2018). Procura apresentar uma crítica construtiva para futuras conferências. Este evento reuniu muitos académicos, de quatro continentes, e deu a conhecer investigações sobre as artes marciais e desportos de combate mais conhecidas (e.g., judo e taekwondo), assim como outras menos investigadas (e.g., o silat da Malásia e diversas artes marciais polacas). As apresentações incidiram sobre os estudos de tipo qualitativo e quantitativo e abrangeram diversas disciplinas académicas. Esta conferência teve a duração de três dias e foi bem organizada e dirigida. Algumas mudanças de programação poderiam maximizar a experiência geral dos participantes em futuros eventos da IMACSSS.

Palavras-chave: Artes marciais; desportos de combate; investigação científica; reuniões científicas; congressos; IMACSSS.

\section{Introduction}

The $7^{\text {th }}$ International Congress of the International Martial Arts and Combat Sports Scientific Society (IMACSSS) and the $4^{\text {th }}$ World Scientific Congress of Sports and Martial Arts was held at the University of Rzeszów (Rzeszów, Poland) on October 17-19, 2018. These conferences are held to further the knowledge and expertise of martial arts and combat sport researchers. All presenters were required to submit their research papers, which were peer-reviewed and scored; the lower scoring papers were presented in the poster session while the more well-received papers were

${ }^{*}$ E-mail: beowulf600@gmail.com 
grouped into plenary or thematic sessions. Previous IMACSSS conferences have been held in Genoa, Italy (see Vertonghen, 2012); Tsukuba, Japan (see Cynarski \& Kubala, 2013); Brno, the Czech Republic (see Bugala, 2015); and other international venues. Headquartered at the University of Rzeszów and presided over Professor Wojciech J. Cynarski (PhD), this year's conference returned to its home for the first time since 2014 (see Pawelec, Słopecki, Sieber, and Rut, 2014). The combined conferences drew more than 50 scholars, researchers, and demonstrators from North America, Europe, Asia, and Oceania (Figure 1).

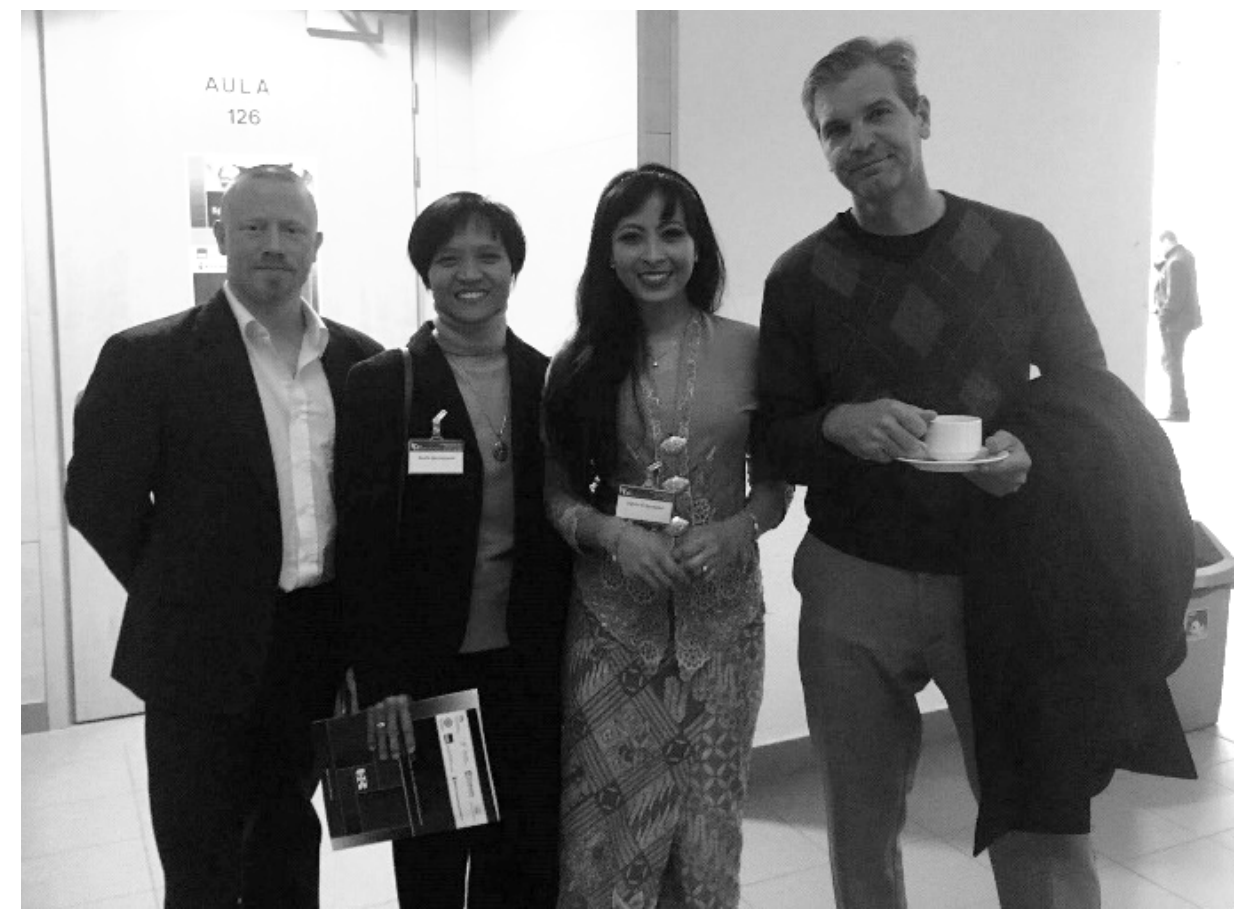

Figure 1. Diverse presenters at the conference. From left to right: (author) John A. Johnson, PhD (USA; professor at Keimyung University, Korea); Reylin Maciejewski, PhD (Philippines; professor at Keimyung University, Korea); Dahlia Al-Syurgawi (Malaysia; faculty at Universiti Teknologi MARA System, Malaysia); and Roland Solymos (Hungary). Photo courtesy of Roland Solymos.

\section{The Conference}

IMACSSS aims to expand and promote martial arts and combat sports research. Its members span the globe and include researchers and scholars from all academic disciplines in which martial arts and combat sports may be researched. The society organizes this congress annually in addition to holding smaller conferences periodically as well. Organizing conferences such as this one provides unique challenges due to the myriad of topics possible (see Jennings, 2017), since martial arts and combats sport research touches on nearly every imaginable academic discipline. As evidenced by some of this year's presentations, interdisciplinary approaches are also becoming widely accepted.

At the 2018 congress, social and natural science articles were presented in three plenary sessions, three thematic sessions, and one poster session. On October 17, 2018, as part of the Congress, there was a solemn ceremony to observe the $25^{\text {th }}$ anniversary of the Idokan Poland Association (IPA), which was the co-organizer of the Congress. All conference participants could attend and participate, and the medium-sized conference hall was filled with hundreds of students and conference participants. Later that morning, the IMACSSS general meetings and elections were held.

The first plenary session was held after the elections. Professor Fuminori Nakiri, professor at Waseda University (Tokyo, Japan) and president of the Japanese Academy of Budo, presented his researched entitled "Research on Safety Measures for Kendo Equipment for Prevention of Injury in Budo (Kendo)" in the conference's keynote speech. He detailed injuries sustained by Kendo 
practitioners, especially focusing on eye injuries from shards cast from splintered shinai (bamboo practice swords). Carbon shinai, which are made from wooden chips conjoined with adhesive and then covered with carbon graphite and plastic, are much suppler and springier than the traditional all-bamboo shinai, thus reducing the possibility of the shinai shattering. According to Professor Nakiri, this research has changed Kendo manufacturing standards.

During the first plenary session later that afternoon, Professor Kurt Weis (Technical University of Munich; Munich, Germany) presented "Kalaripayattu - An Ancient South Indian Martial Art as a Source, Mirror and Example for Martial Arts, Body Arts and Holistic Health Techniques." He not only introduced the little-researched Indian martial art also but discussed its overall focus on healing through massage and other techniques as well as the hypothesis that it is the primordial martial art that predates all others. During the panel discussion afterwards, Professor Weis addressed the latter issue stating his sources had self-reported Kalaripayattu's origin at different periods of time, implying that, like other martial arts, its exact origin is indeterminable. Later in the session, Professor Sergio Raimondo presented his findings on the impact Taijiquan on cancer treatment. The positive findings of this study have obvious worldwide interest and implications. While not necessarily intended, Professor Raimondo's presentation also indicated further studies on the convergence of Eastern and Western medicines may open new possibilities and treatments for global health issues.

On the following day, the second plenary session was held in the morning, and the three thematic sessions were held in the early afternoon. In a presentation relevant to all attendees regardless of academic discipline, Professor Carlos Gutiérrez-García reported on the various journals and academic groups promoting martial arts and combat sports research. His findings, namely that there are now twelve academic journals that cover this research field, was informative for all attendees as it named where they can submit their articles as well as the various journals' merits and demerits (e.g., publishing costs, journal rankings, languages published in, etc.).

The poster session was held from the late morning to the early afternoon on the second day, allowing presenters and attendees to take their time to visit the session during their lunch break. In the afternoon, thematic session presenters were separated into kinesiology, psychology of sport, and social issue sessions. Martial art workshops and showcases were held in the early evening as well. The highlights of the evening were the Ukrainian traditional self-defense (Figure 2), Polish stick fighting, Japanese Aiki-jujutsu, and Malaysian Silat for Children workshops in which presenters and attendees were invited to train with masters of those arts.

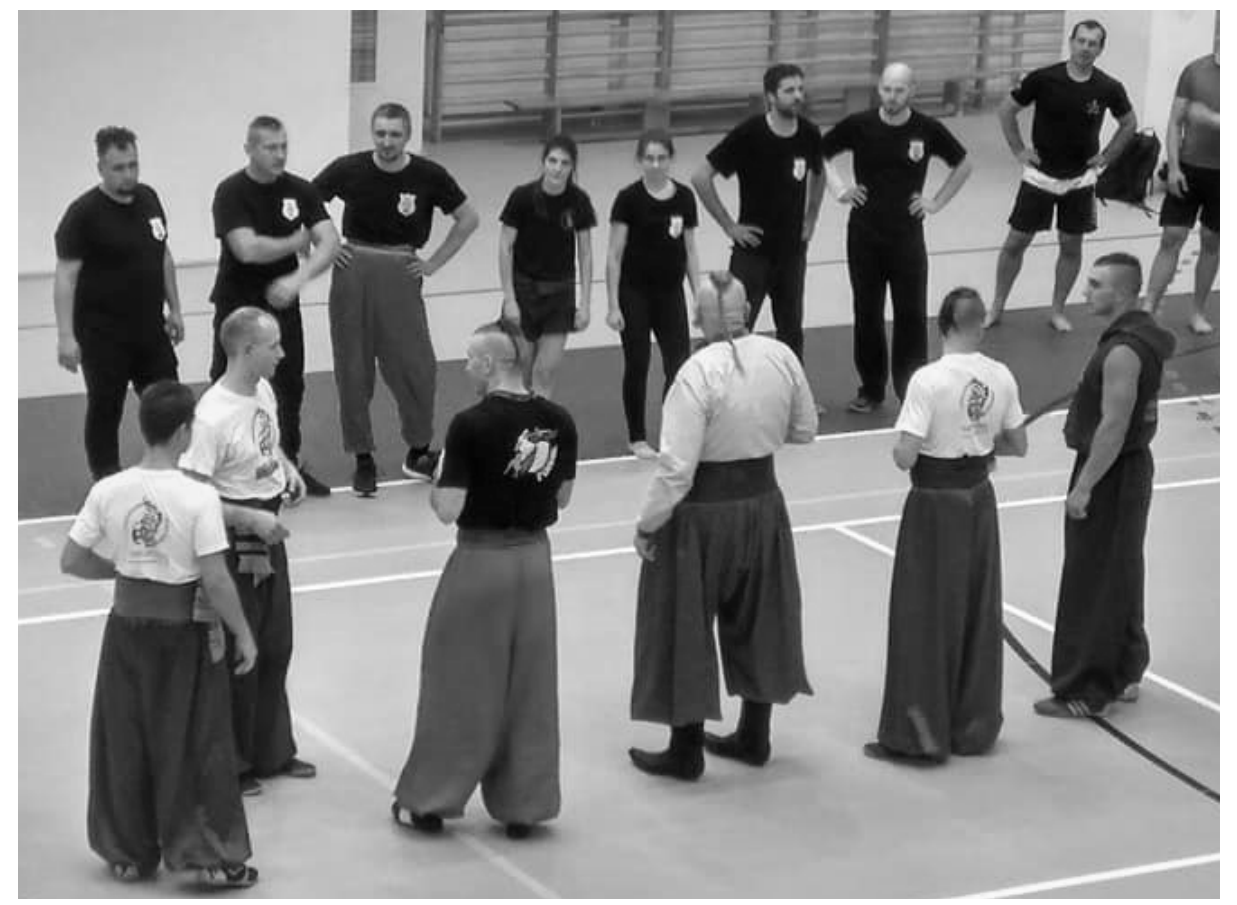

Figure 2. Traditional Ukrainian self-defense workshop. Photo courtesy of IMACSSS. 
The final day of the conference, October 19, included the third plenary session and the closing ceremony. This day saw several excellent presentations on topics including Professor Stefania Skowron-Markowska (University of Wrocław; Wrocław, Poland) who presented on the Shaolin Temple's most recent challenges in teaching Kung Fu and Jožef Šimenko's (University of Ljubljana; Ljubljana, Slovenia) presentation on a case study of the use of isokinetic ACL rehabilitation in Judo. Both presenters received very positive reactions and drew several questions during the discussion. In addition, during the closing ceremony, various awards were presented to individuals who have long-supported or worked for IMACSSS, including the recently-retired IMACSSS general secretary, Dr. Krzysztof Kubala.

Two forthcoming IMACSSS conferences were also announced in the conference's final session. The next IMACSSS conference will be held in in the Polytechnic Institute of Viseu in Portugal in October 2019, while the 2020 conference will be in Putrajaya, Malaysia. Although the location of the 2021 IMACSSS conference has yet to be determined, the 2022 conference will most likely return to Rzeszów, Poland. Also, it was announced that the conferences' proceedings are forthcoming and shall be published by in the journal Ido Movement for Culture.

\section{Conclusions}

Many presenters congratulated Professor Cynarski and the organizing committee for the excellent conference. Judging from Professor Gutiérrez-García's presentation on the state of martial arts journals and comments made by other presenters, few avenues are available for researchers to present and publish their findings in martial art-specific journals. While Professor Gutiérrez-García did state many non-martial art journals in other academic disciplines do publish research, academic conferences of this sort are rare. This conference, however, gathers researchers who are experts in the martial arts, whereas other academic conferences are discipline-specific in nature and audience members may not be as familiar with martial arts and combat sports issues affecting the field today. For example, the discussion of traditional versus innovation in martial arts and combat sports, which was discussed in the first plenary session, would not be of interest to sport scientists, but is of tremendous importance to martial arts researchers. Thus, the IMACSSS conferences are vital to the continuance of research specific to the martial arts by permitting like-minded researchers to congregate and explore current issues in martial arts and combat sports. To further that goal, the conference proceedings will be published as they were four years ago (see Cynarski \& Niziol, 2014) in the Web of Science database.

The quality and quantity of the presentations has improved over the past couple of IMACSSS conferences. During the discussion panels and the question and answer sessions, few (if any) challenges to the researchers and their methods were voiced, a rare occurrence at any conference. Instead, participants inquired about researchers' outcomes and the nature of the martial arts studies in general. Qualitative and quantitative presentations from disciplines ranging from anthropology to international relations to biomechanics moreover demonstrated the growing breadth of martial arts and combat sports research. The relaxed and friendly atmosphere of the conference also facilitated these types of exchanges between participants.

As can be inferred from the above, the conference was organized and executed well. There were numerous volunteers and translators on hand to ensure the events ran smoothly, and outside of a couple of typical technical glitches, only a couple of delays were encountered. Of special value to this conference was the inclusion of presentations on lesser-researched martial arts: the aforementioned Kalaripayattu presentation and Malaysian Silat presentations and workshop were of high quality, and one of the first-ever studies in English on Canary Island Wrestling was presented at the conference. This indicates that martial arts research is expanding away from Olympic combat sports such as Judo and Taekwondo and martial arts of national interest like Kung Fu and Kendo, although all of those were represented at this conference as well. Additionally, the inclusion of demonstrations of several little-known Polish and Ukrainian martial arts not only helped highlight the rich culture and tradition of the host country but expand the participants' knowledge of martial arts in general. 
Despite the very positive responses of the researchers in attendance, some recommendations for future IMACSSS conferences are warranted. Interdisciplinary conferences are difficult to organize due in part because of their "the myriad of styles, technique and methods" and the varied pedagogies (Jennings, 2017, p. 102). The conference's organizing committee therefore was challenged to group presentations into disciplinary categories (i.e., the kinesiology, psychology of sport, and social issue thematic sessions), necessitating all attendees and presenters to be grouped into the multiple plenary sessions. The plenary sessions were consequently a hodgepodge of often unrelated topics. While this enabled everyone to gather and discuss the various topics from multidisciplinary perspectives, it also meant attendees were prevented from visiting other presentations held during thematic sessions since they were isolated into their own sessions. A more general categorization of topics, such as grouping according to social or natural sciences, would create fewer plenary sessions and consequently allow attendees to pick and choose which presentations they could attend with greater ease. Spreading out the thematic sessions over the three days rather than holding them simultaneously on the second day would further maximize participants' exposure to overall current research trends in their fields.

Nevertheless, there was no doubt that the $7^{\text {th }}$ International Congress of the IMACSSS and the $4^{\text {th }}$ World Scientific Congress of Sports and Martial Arts more than succeeded in furthering attendees' knowledge and expertise in martial arts and combat sports. With the next two conferences confirmed, IMACSSS is virtually guaranteed to continue its growth and contributions to martial arts and combat sports research.

\section{References}

Bugala, M. (2016). Report on the 4th International Martial Arts and Combat Sports Scientific Society (IMACSSS) Symposium. Revista de Artes Marciales Asiáticas, 10(2), 135-137. doi: $10.18002 /$ rama.v10i2.3231

Cynarski, W. J., \& Kubala, K. (2013). JAB and IMACSSS conference - Tsukuba 2013. On scientific, budo studies and cultural tourism. Ido Movement for Culture. Journal of Martial Arts Anthropology, 13(4), 25-34. doi: 10.14589/ido.13.4.4

Cynarski, W. J., \& Niziol, A. (Eds.). (2015). Proceedings of the $3^{\text {rd }}$ IMACSSS International Conference, and $3^{\text {rd }}$ World Scientific Congress of Combat Sports and Martial Arts. Rzeszów: Rzeszow University. Retrieved from: http://wf.ur.edu.pl/Dzialalnosc-naukowa/Konferencjecykliczne/Combat-Sports/2014csma/Proceedings-IMACSSS-2014.aspx

Jennings, G. (2017). Martial arts pedagogies and practice: A report on the contributions to coaching knowledge. Revista de Artes Marciales Asiáticas, 12(2), 101-105. doi: $10.18002 /$ rama.v12i2.5152

Pawelec, P., Słopecki, J., Sieber, L., Rut, P. (2014). Scientific and martial arts' tourism. The case study of the $3^{\text {rd }}$ IMACSSS International Conference and Congress. Ido Movement for Culture. Journal of Martial Arts Anthropology, 15(1), 46-56. doi: 10.14589/ido.15.1.7

Vertonghen, J. (2012). Report on the first International Martial Arts and Combat Sports Scientific Society (IMACSSS) Conference - "Game, Drama, Ritual in Martial Arts and Combat Sports". Revista de Artes Marciales Asiáticas, 7(1), 44-47. doi: 10.18002/rama.v7i1.422

\section{Author's biographical data}

John A. Johnson (USA) is an assistant professor in the Department of Taekwondo at Keimyung University (Daegu, South Korea). He received his PhD from the Department of Taekwondo at Kyung Hee University (Suwon, South Korea), and was the first ITF Taekwon-Do practitioner to do so. Dr. Johnson's research focuses on Taekwondo international relations, pedagogy, and philosophy, but he has published in other academic fields as well. He is the executive director of the International Association for Taekwondo Research (www.actataekwondo.com) and vice president of the International Academic Conference for Taekwondo (www.iactkd.com). Email: beowulf600@gmail.com 